\title{
Deprivation level and choice in pigeons: A test of within-trial contrast
}

\author{
Marco Vasconcelos and Peter J. Urcuioli \\ Purdue University, West Lafayette, Indiana
}

\begin{abstract}
Within-trial contrast has been proposed as a mechanism underlying preferences for stimuli that follow relatively more aversive events over stimuli that follow less aversive events. In this study, we manipulated deprivation level to test within-trial contrast predictions. In Experiment 1, pigeons encountered two discriminative stimuli, one presented when they were deprived and the other when they were prefed. When later given a choice between the two stimuli, pigeons strongly preferred the stimulus encountered when deprived, independently of their deprivation level at test. In Experiment 2, pigeons learned two simultaneous discriminations, one when deprived and the other when prefed. Here, subsequent tests between the two $\mathrm{S}^{+}$or the two $\mathrm{S}^{-}$stimuli revealed no consistent preferences. These contrasting findings suggest that differential aversiveness is necessary but not sufficient to induce preferences via within-trial contrast.
\end{abstract}

Most animal research on choice and preference has focused on the effect of consequent variables such as rate, delay, quality, and amount of reinforcement for responding (e.g., Chung \& Herrnstein, 1967; Herrnstein, 1961; Miller, 1976). Recent studies, however, have suggested that animals may also exhibit strong preferences that depend on events that precede the discriminative stimuli presented as choice alternatives. In particular, avians show a preference for discriminative stimuli that follow ostensibly more aversive events over those that follow less aversive events. For example, avians have been shown to prefer discriminative stimuli that follow high effort (Clement, Feltus, Kaiser, \& Zentall, 2000; Kacelnik \& Marsh, 2002), long delays to reinforcement (DiGian, Friedrich, \& Zentall, 2004), and the absence of food (Friedrich, Clement, \& Zentall, 2005) over stimuli that follow low effort, short delays, and presence of food, respectively.

One explanation for these findings is that the preferred stimuli have greater conditioned reinforcing value because of greater contrast between an antecedent aversive state and a subsequent positive state generated when responding to the discriminative stimulus is reinforced (Clement et al., 2000; Clement \& Zentall, 2002; Friedrich \& Zentall, 2004; Singer, Berry, \& Zentall, 2007; Zentall, Clement, Friedrich, \& DiGian, 2006). Zentall and colleagues call this explanation within-trial contrast (e.g., Zentall \& Singer, 2007a) because it involves a discrepancy between these hypothesized states within each conditioning trial.

In the seminal article reporting this effect, Clement et al. (2000) trained pigeons concurrently on two simultaneous discriminations in which the discriminative stimuli were obtained by pecking a center-key stimulus either once or multiple times (low- and high-effort trials, respectively). After acquiring both discriminations to high and stable levels of accuracy, pigeons received periodic, nondifferentially reinforced probe trials on which they chose between the two $\mathrm{S}^{+}$stimuli or between the two $\mathrm{S}^{-}$stimuli. Clement et al. (2000) found a nearly $70 \%$ preference for the higheffort $\mathrm{S}^{+}$and a nearly $85 \%$ preference for the high-effort $\mathrm{S}^{-}$over the corresponding low-effort stimuli, a result they termed the work ethic effect.

However, we (Vasconcelos, Urcuioli, \& Lionello-DeNolf, 2007a) were unable to replicate this effect, despite repeated attempts to do so (Experiments 1-5) and independent evidence for the differential aversiveness of low- versus higheffort trials (Experiment 6). Besides calling into question the reliability of the work ethic effect (see Vasconcelos, Urcuioli, \& Lionello-DeNolf, 2007a, 2007b; Zentall \& Singer, 2007b), our inability to replicate this particular behavioral preference suggests that other proposed (or likely) manifestations of within-trial contrast should be examined. In this article, we test another prediction of this hypothesized mechanism using a manipulation we feel should also generate the required ingredients to induce behavioral preferences - deprivation level during learning.

Kacelnik and his colleagues have recently shown that European starlings and grasshoppers prefer stimuli previously encountered under a state of high deprivation over stimuli previously encountered under a state of low deprivation, regardless of the animals' deprivation level at test (Marsh, Schuck-Paim, \& Kacelnik, 2004; Pompilio \& Kacelnik, 2005; Pompilio, Kacelnik, \& Behmer, 2006). For example, Marsh et al. either food deprived starlings or prefed them before each training session, during which the starlings learned to peck to two discriminative stimuli,

M. Vasconcelos, marcov@psych.purdue.edu 
one presented when they were food deprived and the other when they were prefed. Later, when given a choice between the discriminative stimuli, starlings preferred the one to which they had responded when food deprived.

According to Kacelnik and his colleagues, the fitness (or utility) versus reserves function is often concave, so two options of equal objective value can have different subjective values if encountered under different levels of deprivation (Marsh et al., 2004; Pompilio \& Kacelnik, 2005; Pompilio et al., 2006). In other words, the value of a particular stimulus depends on the fitness gains with which it is associated during training. Consequently, food obtained by responding to a stimulus while very hungry will impart greater value to that stimulus than will food obtained by responding to a stimulus while not very hungry (but see Capaldi, Myers, Campbell, \& Sheffer, 1983). Those differential values, in turn, should be apparent in a preference for the former over the latter stimulus.

Although couched in more functional terms, this explanation is similar to (and, perhaps, indistinguishable from) within-trial contrast, especially if one assumes that sessions run under high versus low deprivation (i.e., very hungry vs. not-so-hungry conditions) constitute blocks of multiple trials during which large versus small degrees of contrast are present. Thus, if high hunger is relatively more aversive for pigeons than low hunger, food reinforcement for responding to a stimulus in the former situation should generate relatively greater contrast, and thus a preference for that stimulus. We tested this prediction here.

\section{EXPERIMENT 1}

Experiment 1 was modeled after Marsh et al.'s (2004) experiment with starlings. Two discriminative stimuli were presented in separate sessions: one when pigeons were at $80 \%$ of their free-feeding body weight (high deprivation) and the other when they were fed prior to the experimental session (low deprivation). After an equal number of training sessions under each energetic state, pigeons were given choice trials in which the two discriminative stimuli were presented simultaneously.

\section{Method}

\section{Subjects}

Four White Carneaux retired breeders obtained from the Palmetto Pigeon Plant (Sumter, SC) participated in the experiment. Two had limited experience unrelated to the contingencies they encountered here. Upon arrival in the lab, all had continuous access to Purina ProGrains in order to determine their free-feeding body weights. Each pigeon was housed individually in stainless steel, wire-mesh cages in a temperature- and humidity-controlled colony room on a $14: 10 \mathrm{~h}$ day:night cycle with lights on at 07:00. Grit and water were always available in the home cage. During experimental participation, postsession food rations were provided in the home cage only when food intake in a session was insufficient to maintain the target body weight.

\section{Apparatus}

Two BRS/LVE (Laurel, MD) experimental chambers, consisting of Model PIP-016 three-key panels inside Model SEC-002 enclosures with an aluminum grid floor, were used. The pigeons' compartment in each chamber was $36.8 \mathrm{~cm}$ high $\times 30.5 \mathrm{~cm}$ wide $\times 34.3 \mathrm{~cm}$ deep.
Stimuli were displayed via in-line projectors (Model IC-901-IDD) mounted behind the keys, each $2.5 \mathrm{~cm}$ in diameter, spaced $8.3 \mathrm{~cm}$ apart, center to center, and positioned approximately $25 \mathrm{~cm}$ from the grid floor. The side-key projectors could display blue, yellow, green, and red homogeneous fields. The center key was not used in this experiment. A partially covered General Electric 1829 bulb $5.7 \mathrm{~cm}$ above the center key directed light toward the ceiling of the enclosure to provide general chamber illumination. Food (Purina ProGrains) could be accessed through a $5.8 \times 5.8 \mathrm{~cm}$ opening centered approximately $13 \mathrm{~cm}$ below the center key; when raised, the food magazine was accompanied by lighting a small miniature bulb (ESB-28). A constantly running blower fan attached to the enclosure provided ventilation and masking noise. An IBM-compatible 386 computer in an adjacent room controlled the presentation and recording of all events via an interface connected to the experimental apparatus.

\section{Procedure}

Preliminary training. The experimentally naive birds were initially trained to eat quickly and reliably from the lit food magazine, after which pecking the side keys was shaped via the method of successive approximations. During these two 20-trial shaping sessions, a single peck to the stimulus appearing on each trial turned it off and produced $3 \mathrm{sec}$ of access to food. Successive trials were separated by a 4-sec intertrial interval (ITI). The color green was used for shaping in the first session and red in the second, each color appearing equally often and on both side keys. Next, all pigeons learned to obtain food by pecking at the red and green stimuli on a self-initiated fixed-interval (FI) schedule of reinforcement, the value of which was raised to $6 \mathrm{sec}$ across four sessions. Completion of the FI requirement immediately turned off the stimulus appearing on each trial and produced food. There were 16 stimulus presentations per session, with each hue appearing equally often and on both side keys. The houselight was turned off during stimulus presentation and food reinforcement and was on throughout the ensuing 45-sec ITI.

Baseline Training I. Next, pigeons received 12 training sessions, during 6 of which they were at $80 \%$ of their free-feeding body weight (deprivation sessions) and during 6 of which they were fed $7 \%$ of their free-feeding body weight $30 \mathrm{~min}$ prior to the experimental session (prefeeding sessions). Independently of session type, all birds were weighed $30 \mathrm{~min}$ prior to the experimental session. Deprivation and prefeeding sessions occurred in a pseudorandom order, with the constraints that neither could occur more than two times in a row and that each occurred in one of the last two baseline training sessions. For half of the birds, the last baseline training session was a deprivation session, whereas for the other half it was a prefeeding session. For 2 pigeons, red was presented during deprivation sessions and green during prefeeding sessions; for the remaining 2 pigeons, these contingencies were reversed. Each session contained 20 trials separated by a 45 -sec ITI. Each trial began when one of the side keys was illuminated. The first peck to the side-key stimulus initiated the FI 6-sec schedule; the first peck to that stimulus after 6 sec had elapsed turned the keylight off and raised the food hopper. To avoid postsession feeding, the reinforcement duration was sporadically adjusted (between 3 and $6 \mathrm{sec}$ ) across sessions, but it was constant within a session (and equal for deprivation and prefeeding sessions). The houselight was on during the ITI and off at all other times.

Preference Test I. A single 20-trial test session immediately followed Baseline Training I. Two birds were tested at $80 \%$ of their free-feeding body weight, and the remaining 2 were fed $7 \%$ of their free-feeding body weight prior to the test session. Each trial involved a choice between the stimulus presented during deprivation sessions and the stimulus presented during prefeeding sessions. All trials commenced with the presentation of the two stimuli on the side keys, with left-right locations counterbalanced across test trials. A single peck to either side key turned off the other side key and initiated an FI 6-sec schedule of reinforcement. Once the FI requirement was met, food reinforcement randomly occurred $50 \%$ of the time, independently of which stimulus was initially pecked. 
Baseline Training II. Next, pigeons were returned to baseline training for 12 additional sessions, 6 deprivation and 6 prefeeding, in a pseudorandom order subject to the same constraints as before.

Preference Test II. A second test session followed the end of the second baseline phase, with each pigeon tested under the opposite deprivation state vis-à-vis its first test.

\section{Results}

\section{Baseline Training I and II}

The average numbers of pecks at the stimuli presented during deprivation and prefeeding sessions were 17.2 and 15.5, respectively. A one-way repeated measures ANOVA yielded no significant effect of session type during either Baseline Training I or II [largest $F(1,3)=4.14]$. The .05 level of significance was employed in these and all subsequent analyses.

\section{Preference Tests I and II}

Figure 1 shows each bird's preference during testing for the stimulus they encountered while under food deprivation during training (hereafter called the deprivation stimulus). The results from the first and second test ses-

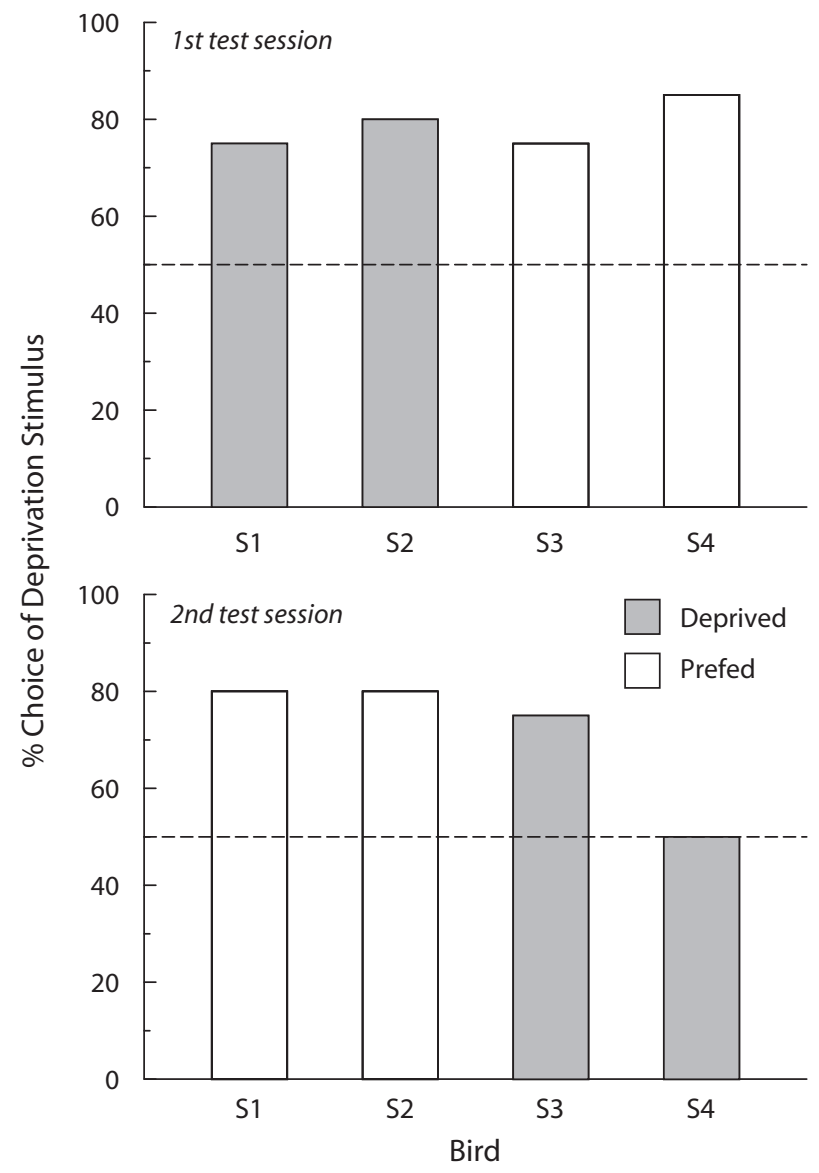

Figure 1. Average percentage choices of the deprivation stimuli from training on test trials in Experiment 1. Filled bars show the results from pigeons deprived during the test session; unfilled bars show the results from pigeons fed prior to the test session. Top panel: Preference data from the first test session. Bottom panel: Preference data from the second test session. sions appear in the top and bottom panels, respectively, and are broken down according to the bird's deprivation level at test (filled vs. unfilled bars). The mean percentages of trials on which pigeons chose the deprivation stimulus were $78.8 \%$ and $71.25 \%$ in the first and second test sessions, respectively. $t$ tests showed that this preference was significantly higher than chance $[t(3)=12.01]$ in the first test session and marginally higher than chance $[t(3)=2.96, p=.06]$ in the second test session. When we analyzed each subject individually and combined the two test sessions, all pigeons showed a significant preference for the deprivation stimulus (smallest $\chi^{2}=4.9$ ).

Note, also, that preferences for the deprivation stimulus were relatively unaffected by whether pigeons were food deprived or prefed in testing $[70 \%$ vs. $80 \%$, respectively; $F(1,3)=1.41]$. In addition, there was no evidence that pigeons preferred the reinforced stimulus they had most recently pecked prior to testing, since overall the pigeons chose the stimulus presented in the last training session $47.6 \%$ of the time during testing.

\section{Discussion}

The results of this experiment corroborate previous findings with starlings and grasshoppers by showing that when pigeons encounter different discriminative stimuli under different levels of deprivation, they come to prefer stimuli encountered when energetic levels are relatively low (viz., when they are highly deprived). Although the preference in the second test session was only marginally significant because of indifference by 1 subject (S4), this is not surprising, given that nondifferential reinforcement on the test trials should have promoted indifference and that the second test provided the second exposure to nondifferential reinforcement. Despite these factors and any disruptive effects of seeing the two stimuli together in testing (as compared with only one throughout training), pigeons clearly preferred the deprivation stimulus in seven out of eight instances.

In previous demonstrations of within-trial contrast in pigeons, the more- and less-aversive events were experienced within the same training sessions. Here, pigeons experienced only one condition (deprived or prefed) per session. It seems, then, that differential aversiveness (and different amounts of contrast) need not be experienced in close temporal proximity in order to have an impact on preference.

\section{EXPERIMENT 2}

The behavioral effects ascribed to within-trial contrast have been mostly observed following simultaneous discrimination training. In fact, Clement et al. (2000) reported that in a preliminary experiment, pigeons did not exhibit the work ethic effect when training involved forced-choice (i.e., single-stimulus) trials, like those we used in Experiment 1. It is curious, then, that our deprivation manipulation in Experiment 1 and those used by others (Marsh et al., 2004; Pompilio \& Kacelnik, 2005; Pompilio et al., 2006) produced clear behavioral preferences. 
Of course, different independent variables (differential effort vs. differential deprivation) may be responsible for this discrepancy, but other findings suggest that this is not the case. For example, Kacelnik and Marsh (2002) obtained reliable preferences with an effort-based manipulation using single-stimulus trials during training with starlings. In particular, starlings learned to obtain food by pecking one hue after 16 one-meter flights (high-effort trials) and by pecking another hue after 4 one-meter flights (low-effort trials). Later, 10 out of 12 starlings showed a significant preference for the stimulus associated with high effort.

Still, it would seem reasonable to suppose that simultaneous discrimination training should optimize preferences because there should then be less generalization decrement from training to testing (i.e., all trials - training and testing - involve a choice) than would occur when training involves a single stimulus per trial and testing involves two stimuli per trial. In Experiment 2, then, pigeons learned two simultaneous discriminations in training, one during deprivation sessions and the other during prefeeding sessions. After acquiring both discriminations to high levels of accuracy, pigeons were then tested for their preference between the two $\mathrm{S}^{+}$stimuli. In addition, they were also tested separately for their preference between the two $\mathrm{S}^{-}$ stimuli (cf. Clement et al., 2000).

\section{Method \\ Subjects and Apparatus \\ Six White Carneaux retired breeders, obtained from the same sup- plier as in Experiment 1 and housed and maintained as described earlier, served in this experiment. Three were experimentally naive. The nonnaive birds had limited experience unrelated to the pres- ent contingencies. Two operant chambers similar to those used in Experiment 1 were used.}

\section{Procedure}

Preliminary training. Following magazine training, the experimentally naive birds were trained via the method of successive approximations to peck the side keys. All the details of the four shaping sessions were identical to those in Experiment 1, except that four hues (yellow, green, blue, and red) were presented, with order counterbalanced across birds. Next, all pigeons learned to obtain food by pecking each color stimulus on a self-initiated FI 6-sec schedule of reinforcement. Again, all of the details of these preliminary training sessions were identical to those in Experiment 1, except that the above-mentioned four hues were used during these sessions.

Baseline Training I. During baseline training, pigeons learned two simultaneous discriminations, one during deprivation sessions and the other during prefeeding sessions. Red and yellow, as well as green and blue, always appeared together as discriminative stimuli, with each set presented only during deprivation or during prefeeding sessions, counterbalanced across birds. In any given session, each color was shown equally often on the left and on the right key. For half of the birds, red and green served as the $\mathrm{S}^{+}$stimuli (and yellow and blue as the $\mathrm{S}^{-}$stimuli), and vice versa for the other half. Each discrimination trial (20 per session) began with the offset of the houselight and the illumination of both side keys. A single peck to either hue turned off the other side-key stimulus and initiated an FI 6-sec schedule that ended in food reinforcement, if the $\mathrm{S}^{+}$was pecked first, or in nonreinforcement, if the $\mathrm{S}^{-}$was pecked first. A 45 -sec ITI with the houselight on then commenced. To avoid postsession feeding, the duration of food reinforcement varied across sessions as needed, but it was kept constant within a session and was equal for deprivation and prefeeding sessions.
Pigeons were trained to a criterion of one session in which they chose the $\mathrm{S}^{+}$stimuli $90 \%$ or more of the time during each session type. After meeting this criterion, 12 additional overtraining sessions were given -6 deprivation and 6 prefeeding sessions. Throughout training, the two session types occurred in a pseudorandom order, with the constraints that neither occurred more than two times in a row and that each occurred in one of the last two training sessions. For half of the birds, the last baseline session was a deprivation session, whereas for the other half it was a prefeeding session.

Preference Tests I and II. Next, pigeons received a 20 -trial test session. Three birds were tested at $80 \%$ of their free-feeding body weight, and the remaining 3 were fed $7 \%$ of their free-feeding body weight prior to the test session. Each test trial involved a choice between the $\mathrm{S}^{+}$presented during deprivation sessions and the $\mathrm{S}^{+}$ presented during prefeeding sessions. The test trials thus involved choices either between red and green or between yellow and blue. All other details, including the reinforcement contingency, were identical to those described for the test trials in Experiment 1. After this test session, birds received additional baseline training until criterion was recovered, plus two overtraining sessions (one deprivation and one prefeeding) in the same order as the last two sessions prior to testing. A second test session then followed, in which test trials involved a choice between the $\mathrm{S}^{-}$presented during deprivation sessions and the $\mathrm{S}^{-}$presented during prefeeding sessions. Birds were tested at the same deprivation level as in the first test session.

Baseline Training II. After the $\mathrm{S}^{-}$preference test, each bird was returned to baseline training until it met criterion once again. It then received 12 overtraining sessions in a pseudorandom order subject to the same constraints as before. All other details were the same as in Baseline Training I.

Preference Tests III and IV. Finally, birds received two more test sessions, separated by criterion recovery and two additional baseline training sessions. The first test involved a choice between the two $\mathrm{S}^{+}$ stimuli and the second a choice between the two $\mathrm{S}^{-}$stimuli. Birds originally tested at $80 \%$ of their free-feeding body weight were now fed prior to the test sessions, and vice versa for the remaining birds. All other details were the same as in Preference Tests I and II.

\section{Results}

\section{Baseline Training I and II}

Pigeons learned the two simultaneous discriminations rapidly. The average number of sessions to criterion (including the criterion session) during Baseline Training I was 4.0 sessions for the two simultaneous discriminations. During Baseline Training II, pigeons required on average 1.3 and 1.7 sessions to reacquire criterion performance on deprivation and prefeeding simultaneous discriminations, respectively. One-way repeated measures ANOVAs yielded no significant effect of trial type during either Baseline Training I or II $[$ all $F \mathrm{~s}(1,5)<1]$. Likewise, there were no significant differences between the number of sessions to recover criterion performance after Preference Tests I and III [largest $F(1,5)=1.00]$.

During overtraining, pigeons continued to perform accurately on both simultaneous discriminations: $98.6 \%$ and $96.9 \%$ correct for the deprivation and prefeeding simultaneous discriminations, respectively, during Baseline Training I, and $98.3 \%$ and $98.8 \%$ correct, respectively, during Baseline Training II. There were no significant between-discrimination differences [largest $F(1,5)=3.15$ ].

\section{Preference Tests}

Figure 2 shows preferences for the deprivation $\mathrm{S}^{+}$for the first (top panel) and third (bottom panel) test sessions. 


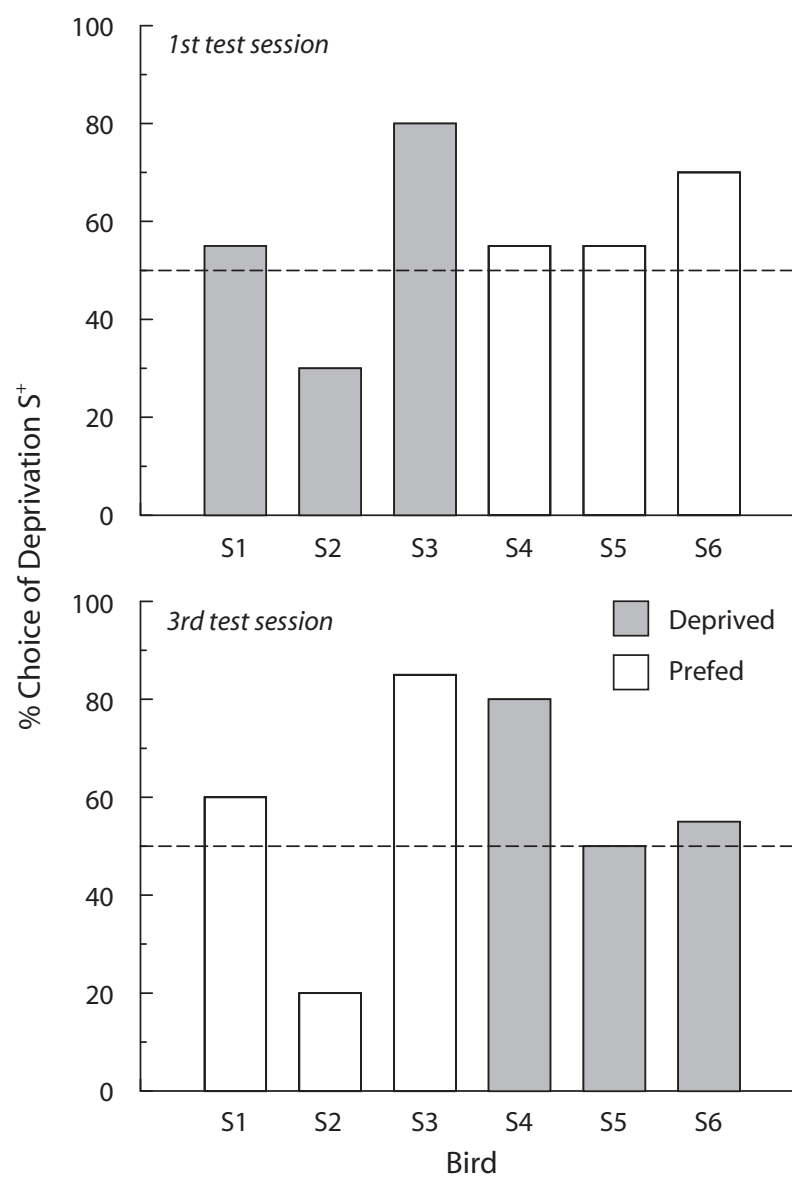

Figure 2. Average percentage choices of the deprivation $\mathbf{S}^{+}$ from training on test trials in Experiment 2. Filled bars show the results from pigeons deprived during the test session; unfilled bars show the results from pigeons fed prior to the test session. Top panel: Preference data from the first test session. Bottom panel: Preference data from the third test session.

Filled bars show the data from pigeons tested under deprivation, and unfilled bars show the data from the prefed animals. On average, the deprivation $\mathrm{S}^{+}$was chosen $57.5 \%$ and $58.3 \%$ of the time on the first and third test sessions, respectively. $t$ tests showed that neither of these preferences deviated significantly from chance [largest $t(5)=$ 1.08]. When the two test sessions were combined, 2 pigeons showed a significant preference for the deprivation $\mathrm{S}^{+}$(smallest $\left.\chi^{2}=4.9\right), 1$ showed a significant preference for the prefeeding $\mathrm{S}^{+}\left(\chi^{2}=10.0\right)$, and the remaining 3 were indifferent (largest $\chi^{2}=2.5$ ).

Figure 3 plots the corresponding preferences for the deprivation $\mathrm{S}^{-}$stimulus. On average, birds chose the deprivation $\mathrm{S}^{-} 55 \%$ and $58.3 \%$ of the time on the second and fourth test sessions, respectively. These preferences were also not significantly different from chance [largest $t(5)=$ 0.56]. Considering both test sessions, 2 pigeons showed a significant preference for the deprivation $\mathrm{S}^{-}$(smallest $\left.\chi^{2}=25.6\right), 2$ showed a significant preference for the prefeeding $\mathrm{S}^{-}$(smallest $\chi^{2}=6.4$ ), and the remaining 2 were indifferent (both $\chi^{2}=1.6$ ).
As in Experiment 1, no effect of deprivation level at test was found: Birds chose the deprivation $\mathrm{S}^{+} 58.3 \%$ of the time when deprived and $57.5 \%$ of the time when prefed; likewise, they chose the deprivation $\mathrm{S}^{-4} 48.3 \%$ and $65.0 \%$ of the time when deprived and when prefed, respectively. One-way repeated measures ANOVAs performed on these data showed no significant effects [largest $F(1,5)=1.61$ ]. No carryover effects of the preceding training session were observed either. Pigeons preferred the $\mathrm{S}^{+}$from the preceding training session, on average, $50.4 \%$ of the time, and similarly, pigeons avoided (i.e., did not choose) the $\mathrm{S}^{-}$from the preceding training session $36.7 \%$ of the time, on average.

\section{Discussion}

In contrast to Experiment 1, when different simultaneous discriminations were trained under high and low deprivation, there was no overall preference for either the $\mathrm{S}^{+}$or the $\mathrm{S}^{-}$experienced during high deprivation. We expected that greater similarity between training and testing would make such preferences more robust or, at a minimum, at

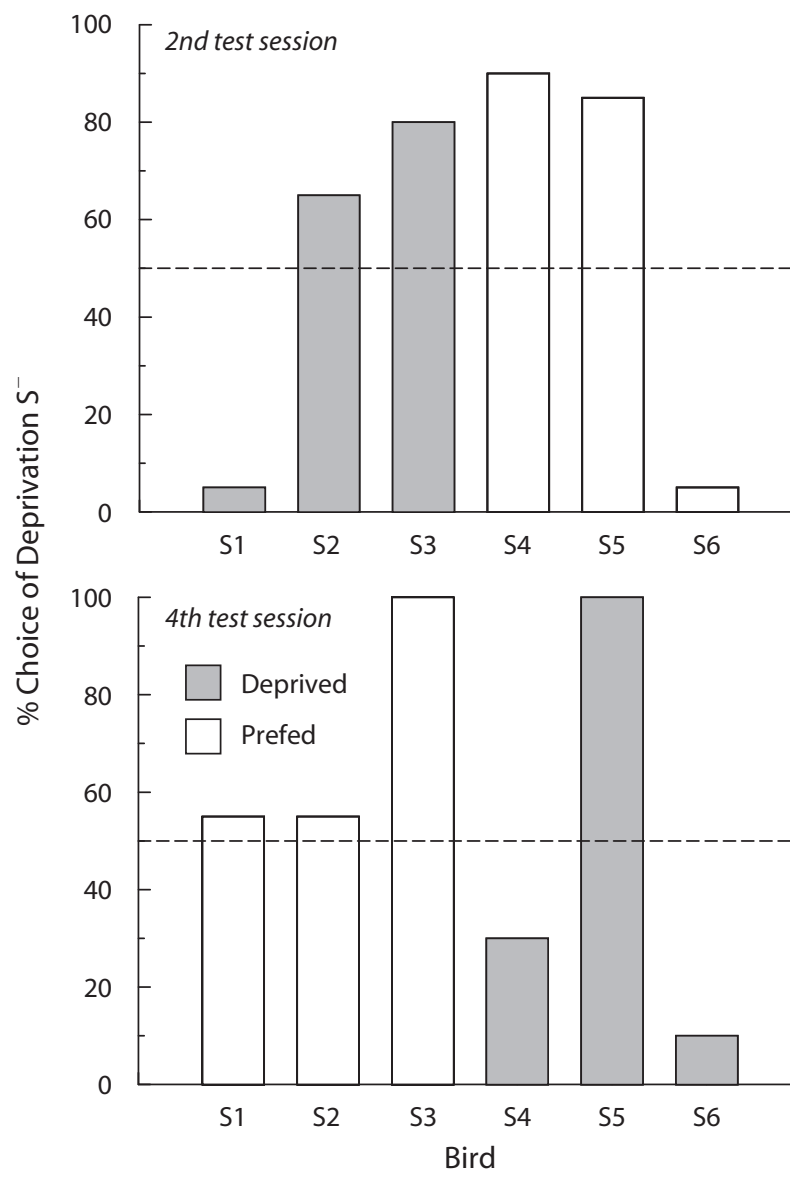

Figure 3. Average percentage choices of the deprivation $\mathrm{S}^{-}$ from training on test trials in Experiment 2. Filled bars show the results from pigeons deprived during the test session; unfilled bars show the results from pigeons fed prior to the test session. Top panel: Preference data from the second test session. Bottom panel: Preference data from the fourth test session. 
least as strong as we observed in Experiment 1. In fact, simultaneous discrimination training appeared to have the opposite effect. Indeed, only 2 out of 6 birds showed a significant preference for the deprivation $\mathrm{S}^{+}$. Why?

One possibility is that whenever two differentially valued stimuli are presented, the lower-value stimulus enhances the value of the higher-value stimulus - a positive contrast effect. Although behavioral contrast has been mainly studied in the context of successive discriminations (e.g., Reynolds, 1961), Clement, Weaver, Sherburne, and Zentall (1998) found evidence for such an effect with simultaneous discrimination training, too. If contrast operates in the context of a simultaneous discrimination training trial, this might have created a ceiling effect on the values of both $\mathrm{S}^{+}$stimuli that, in turn, swamped any effect of the deprivation-level manipulation. Of course, this raises the question of why such contrast did not hinder the behavioral effects ascribed to within-trial contrast and which have been customarily observed after simultaneous discrimination training (see, e.g., Clement et al., 2000; DiGian et al., 2004; Friedrich et al., 2005).

Another possibility is that pigeons did not receive sufficient discrimination training to generate the predicted preference. Zentall and Singer (2007b), for instance, have surmised that preferences indicative of within-trial contrast can be slow to develop in pigeons (e.g., Friedrich \& Zentall, 2004; Singer et al., 2007) and, thus, may require at least $30-40$ training sessions $(3,000-4,000$ trials at 100 trials/ session) to become apparent. However, Arantes and Grace (2008, Experiment 2) recently reported that they were unable to obtain evidence for such preferences even after more than 100 sessions $(\sim 10,000$ trials). Similarly, in a recently completed study, we too were unable to obtain the preference effect after more than 60 sessions $(6,000$ training trials) with a signaled high- versus low-effort simultaneous discrimination task (Vasconcelos \& Urcuioli, 2007).

Moreover, it should also be noted that the amount of training that pigeons received in this experiment, which resulted in no consistent preference for the deprivation $\mathrm{S}^{+}$, was the same as in Experiment 1, in which such a preference was found. Clearly, there is more to this curious discrepancy than amount of training per se.

\section{GENERAL DISCUSSION}

Animals, particularly avians, have been shown to prefer discriminative stimuli that follow relatively more aversive events over stimuli that follow less aversive events, and within-trial contrast has been proposed as a mechanism to explain such preferences (Zentall \& Singer, 2007a). In this article, we investigated the possibility that discriminative stimuli acquire different values for pigeons when reinforced under different levels of deprivation. Specifically, we predicted that pigeons should prefer stimuli encountered under high rather than low deprivation. Experiment 1 confirmed this prediction; Experiment 2, however, did not.

When a single stimulus was presented while pigeons were under each deprivation state (Experiment 1), food reinforcement appeared to impart greater value to the reinforced stimulus experienced under high deprivation. This was shown in subsequent two-choice preference tests: Pigeons more often selected the stimulus previously encountered under high deprivation than the stimulus previously encountered under low deprivation. When simultaneous discriminations were used during training (Experiment 2), however, food reinforcement did not appear to impart such differential value. On average, pigeons were indifferent to the high- versus low-deprivation $\mathrm{S}^{+}$in two-choice preference tests, and were similarly indifferent to the corresponding $\mathrm{S}^{-}$.

Prior studies of within-trial contrast in pigeons have not directly manipulated deprivation level, although Friedrich et al. (2005) reported a conceptually similar manipulation. In their experiment, pigeons learned two simultaneous discriminations in which food preceded the discriminative stimuli for one task, and an equivalent period of no food preceded the discriminative stimuli for the other task. Later, pigeons were given a choice between the two $\mathrm{S}^{+}$stimuli and between the two $\mathrm{S}^{-}$stimuli. Although no significant preference for the no-food $\mathrm{S}^{-}$was observed, pigeons showed a significant overall preference for the $\mathrm{S}^{+}$ preceded by no food. However, this preference depended in part on which antecedent event (food vs. no food) occurred on the test trials themselves. Pigeons were much more likely to choose the no-food $\mathrm{S}^{+}$from training when the test trials began with no food than when they began with food ( $81.2 \%$ vs. $53.1 \%$, respectively). In other words, preference was at least in part contextually dependent. In our experiment, however, deprivation level at the time of testing did not affect pigeons' choices.

The conceptual parallel is that "no food" is akin to high deprivation and "food" is akin to low deprivation. Of course, no food and food in Friedrich et al. (2005) occurred within the same session and varied from one trial to the next, whereas in our experiments, high and low deprivation varied across sessions. Still, our manipulation would seem to entail more extreme variation in the antecedent conditions that purportedly give rise to within-trial contrast (viz., prefeeding an animal $7 \%$ of its free-feeding body weight should cause a much greater shift in its energetic state than should feeding it briefly prior to half of the trials). Besides, experiencing the two antecedent conditions within the same session is clearly not crucial, as the results from our Experiment 1 show.

It might be argued that the results of Experiment 2 indicate that deprivation manipulations of the sort used here do not create the necessary differential aversiveness for the operation of within-trial contrast, and that the significant preference observed in Experiment 1 might have been caused by random factors. We think this is unlikely, given that deprivation manipulations have been shown to be effective in single-stimulus training procedures both with starlings (Marsh et al., 2004; Pompilio \& Kacelnik, 2005) and grasshoppers (Pompilio et al., 2006). Our results with pigeons are consistent with such findings and add to their betweenspecies generality. Also, the fact that we (Vasconcelos et al., 2007a) and others (Arantes \& Grace, 2008) could not replicate the original work ethic effect that was reported using simultaneous discrimination training suggests that this type of training may not be conducive to generating the differential values envisioned by within-trial contrast. 
A somewhat similar pattern of findings can be found in the resistance-to-change literature (e.g., Nevin, 1979; Nevin \& Grace, 2000). Here, too, results differ depending on whether one or two stimuli are presented simultaneously. When multiple schedules are used (akin to our Experiment 1), greater resistance to change in the richer schedule is observed, but when training involves concurrent schedules (akin to our Experiment 2), there is no differential resistance to change across the two concurrently presented alternatives, despite differences in reinforcement frequency for the two alternatives (Bell \& Williams, 2002).

At best, our findings provide further evidence for within-trial contrast (Experiment 1) but, at the same time, suggest that the necessary ingredients for its operation are not completely understood (Experiment 1 vs. 2). When deprivation level is manipulated, differential aversiveness arising from different antecedent conditions or states seems necessary but not sufficient to reveal preferences for stimuli encountered during the more aversive condition. As previously stated, perhaps positive behavioral contrast between simultaneously presented $\mathrm{S}^{-}$and $\mathrm{S}^{+}$ stimuli can explain why such preferences are not evident after simultaneous discrimination training (Clement et al., 1998), although this leaves unanswered the question of why such contrast did not interfere with other within-trial contrast demonstrations involving this training regimen.

If our speculation about the role of the enhanced value of an $\mathrm{S}^{+}$encountered in the context of a simultaneously presented S- (cf. Clement et al., 1998) in masking the effect of deprivation level is true, it should also be possible to "unmask" that effect by reducing the level of the hypothesized enhancement. Unfortunately, it is not entirely clear what manipulations would (or should) be effective in doing so.

For now, it seems clear that the preferences attributed to within-trial contrast depend on the nature of training, at least for pigeons. How and why the ingredients for the operation of this mechanism interact with the training procedure are intriguing questions for future research.

\section{AUTHOR NOTE}

This research was supported by National Institute of Mental Health Grant MH 66195 to P.J.U. The data were previously reported at the Joint Meeting of the Experimental Psychology Society and the Psychonomic Society (Edinburgh, July 2007). Correspondence concerning this article should be addressed to M. Vasconcelos, Department of Psychological Sciences, Purdue University, 703 Third Street, West Lafayette, IN 47907-2081 (e-mail: marcov@psych.purdue.edu).

\section{REFERENCES}

Arantes, J., \& Grace, R. C. (2008). Failure to obtain value enhancement by within-trial contrast in simultaneous and successive discriminations. Learning \& Behavior, 36, 1-11.

Bell, M. C., \& Williams, B. A. (2002). Preference and resistance to change in concurrent variable-interval schedules. Animal Learning \& Behavior, 30, 34-42.

Capaldi, E. D., Myers, D. E., Campbell, D. H., \& Sheffer, J. D. (1983). Conditioned flavor preferences based on hunger level during original flavor exposure. Animal Learning \& Behavior, 11, 107-115.

Chung, S.-H., \& Herrnstein, R. J. (1967). Choice and delay of reinforcement. Journal of the Experimental Analysis of Behavior, 10, 67-74.

Clement, T. S., Feltus, J. R., Kaiser, D. H., \& Zentall, T. R. (2000).
"Work ethic" in pigeons: Reward value is directly related to the effort or time required to obtain the reward. Psychonomic Bulletin \& Review, 7, 100-106.

Clement, T. S., Weaver, J. E., Sherburne, L. M., \& Zentall, T. R. (1998). Simultaneous discrimination learning in pigeons: Value of $\mathrm{S}^{-}$ affects the relative value of its associated $\mathrm{S}^{+}$. Quarterly Journal of Experimental Psychology, 51B, 363-378.

Clement, T. S., \& Zentall, T. R. (2002). Second-order contrast based on the expectation of effort and reinforcement. Journal of Experimental Psychology: Animal Behavior Processes, 28, 64-74.

DiGian, K. A., Friedrich, A. M., \& Zentall, T. R. (2004). Discriminative stimuli that follow a delay have added value for pigeons. Psychonomic Bulletin \& Review, 11, 889-895.

Friedrich, A. M., Clement, T. S., \& Zentall, T. R. (2005). Discriminative stimuli that follow the absence of reinforcement are preferred by pigeons over those that follow reinforcement. Learning \& Behavior, 33, 337-342.

Friedrich, A. M., \& Zentall, T. R. (2004). Pigeons shift their preference toward locations of food that take more effort to obtain. Behavioural Processes, 67, 405-415.

HERRNSTEIN, R. J. (1961). Relative and absolute strength of response as a function of frequency of reinforcement. Journal of the Experimental Analysis of Behavior, 4, 267-272.

KACELNIK, A., \& MARSH, B. (2002). Cost can increase preference in starlings. Animal Behaviour, 63, 245-250.

Marsh, B., Schuck-Paim, C., \& Kacelnik, A. (2004). Energetic state during learning affects foraging choices in starlings. Behavioral Ecology, 15, 396-399.

Miller, H. L. (1976). Matching-based hedonic scaling in the pigeon. Journal of the Experimental Analysis of Behavior, 26, 335-347.

Nevin, J. A. (1979). Reinforcement schedules and response strength. In M. D. Zeiler \& P. Harzem (Eds.), Reinforcement and the organization of behaviour (pp. 117-158). New York: Wiley.

NeVIN, J. A., \& GRACE, R. C. (2000). Behavioral momentum and the law of effect. Behavioral \& Brain Sciences, 23, 73-130.

Pompilio, L., \& KACELNIK, A. (2005). State-dependent learning and suboptimal choice: When starlings prefer long over short delays to food. Animal Behaviour, 70, 571-578.

Pompilio, L., Kacelnik, A., \& Behmer, S. T. (2006). State-dependent learned valuation drives choice in an invertebrate. Science, 311, 1613-1615.

REYNOLDS, G. S. (1961). Behavioral contrast. Journal of the Experimental Analysis of Behavior, 4, 57-71.

Singer, R. A., Berry, L. M., \& Zentall, T. R. (2007). Preference for a stimulus that follows a relatively aversive event: Contrast or delay reduction? Journal of the Experimental Analysis of Behavior, 87, $275-285$.

VASCONCELOS, M., \& URCUIOLI, P. J. (2007). Extensive training is insufficient to produce the work ethic effect in pigeons. Manuscript submitted for publication.

Vasconcelos, M., Urcuioli, P. J., \& Lionello-DeNolf, K. M. (2007a). Failure to replicate the "work ethic" effect in pigeons. Journal of the Experimental Analysis of Behavior, 87, 383-399.

Vasconcelos, M., Urcuioli, P. J., \& Lionello-DeNolf, K. M. (2007b). When is a failure to replicate not a Type II error? Journal of the Experimental Analysis of Behavior, 87, 405-407.

Zentall, T. R., Clement, T. S., Friedrich, A. M., \& DiGian, K. A. (2006). Stimuli signaling rewards that follow a less-preferred event are themselves preferred: Implications for cognitive dissonance. In E. A. Wasserman \& T. R. Zentall (Eds.), Comparative cognition: Experimental explorations of animal intelligence (pp. 651-667). New York: Oxford University Press.

Zentall, T. R., \& Singer, R. A. (2007a). Within-trial contrast: Pigeons prefer conditioned reinforcers that follow a relatively more rather than a less aversive event. Journal of the Experimental Analysis of Behavior, 88, 131-149.

Zentall, T. R., \& Singer, R. A. (2007b). Within-trial contrast: When is a failure to replicate not a Type I error? Journal of the Experimental Analysis of Behavior, 87, 401-404.

(Manuscript received August 18, 2007;

revision accepted for publication October 10, 2007.) 